\title{
Establishment Of A Strategic Total Direct Mail Model To Bring Customers Into Auto Dealerships
}

Hisatoshi Ishiguro, Aoyama Gakuin University, Japan Kakuro Amasaka, Aoyama Gakuin University, Japan

\begin{abstract}
This paper uses statistical science and mathematical programming to develop a strategic Total Direct Mail Model "TDMM" with the aim of bringing more customers into auto dealerships. The core systems used in the model are (1) a customer purchase data analysis system to increase dealer visits, (2) a DM content optimization system to target customer preferences, (3) a system for strategically determining who should be sent direct mail based on who actually visits the dealership, and (4) a DM promotion system for sales staff to increase market share. These four systems are integrated and strategically applied to promote dealer visits. The authors then apply this model at an actual auto dealership, where they are able to successfully increase dealer visits.
\end{abstract}

Keywords: Marketing; Customer Retention; Direct Mail; Total Direct Mail Model; Statistical Science; Mathematical Programming

\section{NECESSITY OF DIRECT MAIL}

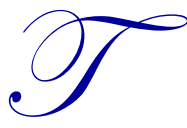

his paper focuses on customer retention, a critical issue at auto dealerships, and discusses a methodology for preventing customer loss. The necessity of direct mail as a tool for retaining premier customers is discussed below.

\subsection{Direct Mail and Customer Retention}

Auto dealerships typically store customer attributes, purchase history, and other information on their clients in a database or similar storage system (Amasaka, 2004). The database is used to identify premier customers, and pinpointing their preferences is critical if the dealership is to prevent them from taking their business elsewhere. The authors consider using a database to help find premier customers and then sending them direct mail to be an effective method of sales promotion.

Kotler and Keller (2006) identified the ability to select your recipients and the ability to offer personalized content as the advantages of direct mail. Piersma and Jonker (2004) studied how often to send direct mail to individual customers in order to establish long-term relationships between the direct mailer and the customers. Jonker et al. (2006) provided a decision support system to determine mailing frequency for active customers based on their behavioral data: their recency, frequency, and monetary (RFM) values. Bell et al. (2006) applied experimental designs to increase direct mail sales. Beko and Jagric (2011) presented demand models for direct mail and periodicals market using time series analysis. Direct mail is notable as an effective way of targeting specific premier customers for sales promotions (Bult and Wansbeek, 2005).

\subsection{Direct Mail and the AIDA Model}

The AIDA model is a well-known advertising information management model developed by St. Elmo Lewis. The model presents the psychology of consumer purchase behavior as a series of four steps: attention, interest, desire, and action (Ferrell and Hartline, 2005; Shimizu, 2004). 
The authors have created a model of customer response for use in auto sales (Amasaka, 2007, 2009). This model is based on the AIDA model and presented in Figure 1. The model allows dealerships to boost the percentage of customers that visit the showroom by using mass media advertising, flyers, magazine ads, and direct mail.

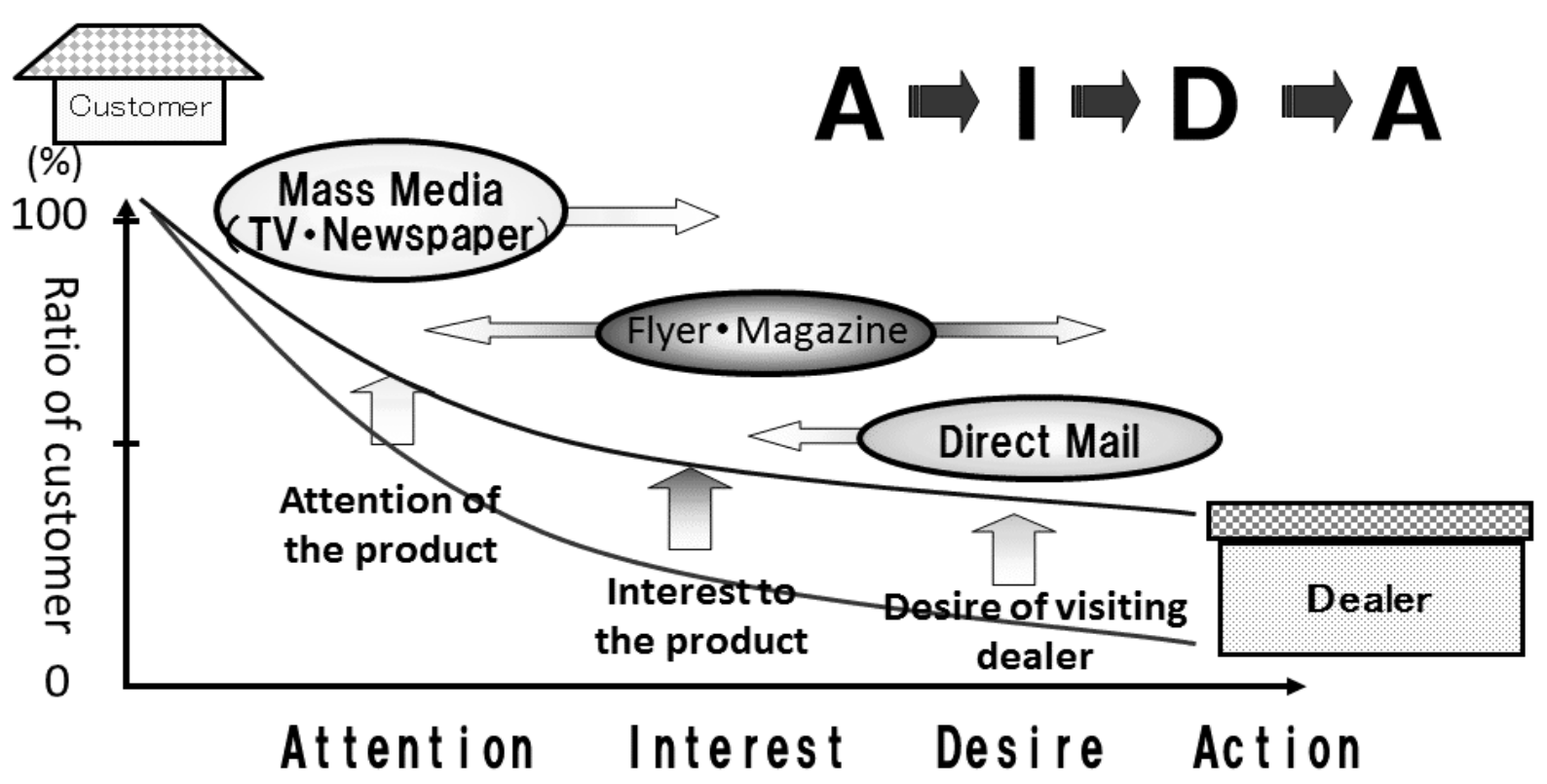

Figure 1: AIDA Model

\subsection{Current Research on Direct Mail Activities} issues:

In studying the current status of direct mail activities at dealerships, the authors identified the following

1. Strategy formulation: target customers and sales concepts are unclear

2. Direct mail content: customer preferences are not accurately identified

3. Recipients: recipients are determined based on experiential knowledge of sales staff, which leads to a high degree of variation in the quality of work performed

4. Approach to customers who visit the dealership: purchase behavior characteristics of individual customer are not well understood

Given these problems, direct mail cannot currently be thought of as effective in all cases. The authors have demonstrated that the percentage of direct mail recipients that visit the dealers is as low as $1-5 \%$, and that the profitability of those customers that do come in is not very high (Ishiguro and Amasaka, 2012; Ishiguro et al., 2010). It is critical that these issues be resolved so that direct mail activities are more efficient (sophisticated). This will help dealerships retain their premier customers and boost their sales. A survey of the literature did not reveal any prior research that successfully addresses these problems.

\section{STRATEGICALLY APPLYING A TOTAL DIRECT MAIL MODEL "TDMM"}

Based on previous direct mail research and studies done on the actual state of direct mail activities, the authors developed TDMM, the strategic application of a Total Direct Mail Model. This model is shown in Figure 2.

As the figure indicates, the model consists of the following four core functions: 
(a) Direct mail strategy formulation: scientific identification of premier customers (Amasaka, 2011)

(b) Direct mail content: development of content based on customer preferences (Kimura et al., 2007)

(c) Mailing process: establishing a process for determining recipients based on customer information and other data (Ishiguro and Amasaka, 2012; Ishiguro et al., 2010)

(d) Customer handling: clearly identifying customer purchase behavior characteristics (Kimura et al., 2007)

Figure 3 shows the authors' approach to practically implementing the above strategies. The related systems are described below.

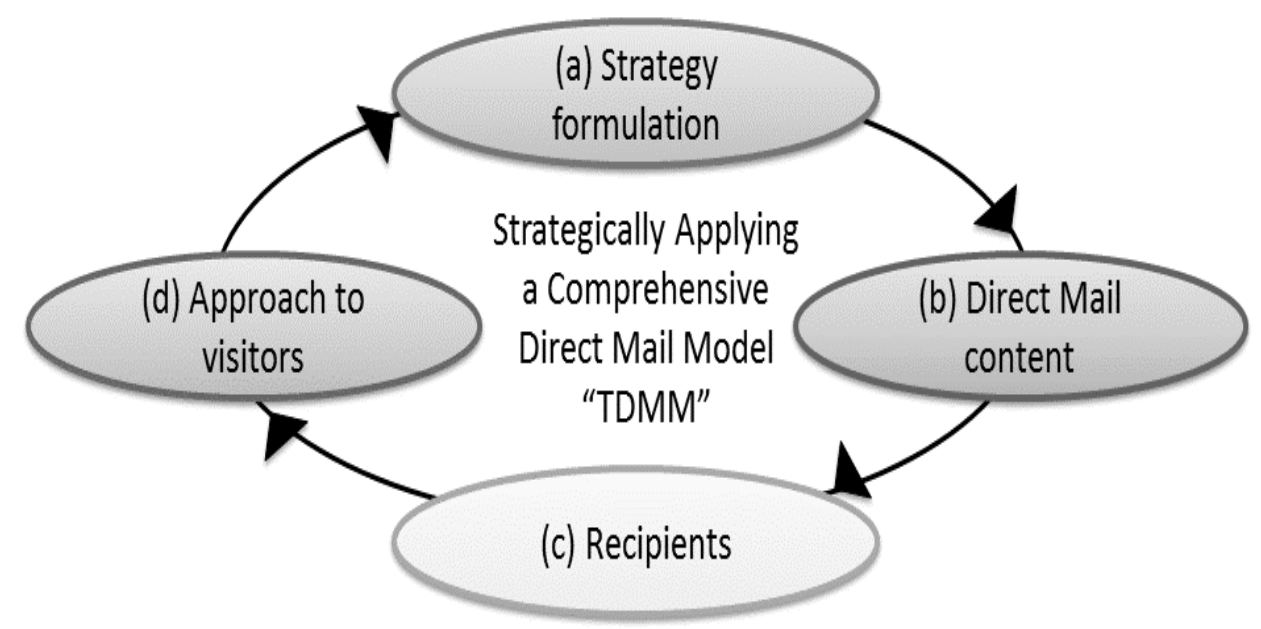

Figure 2: Strategically Applying a Total Direct Mail Model "TDMM": Concept Model

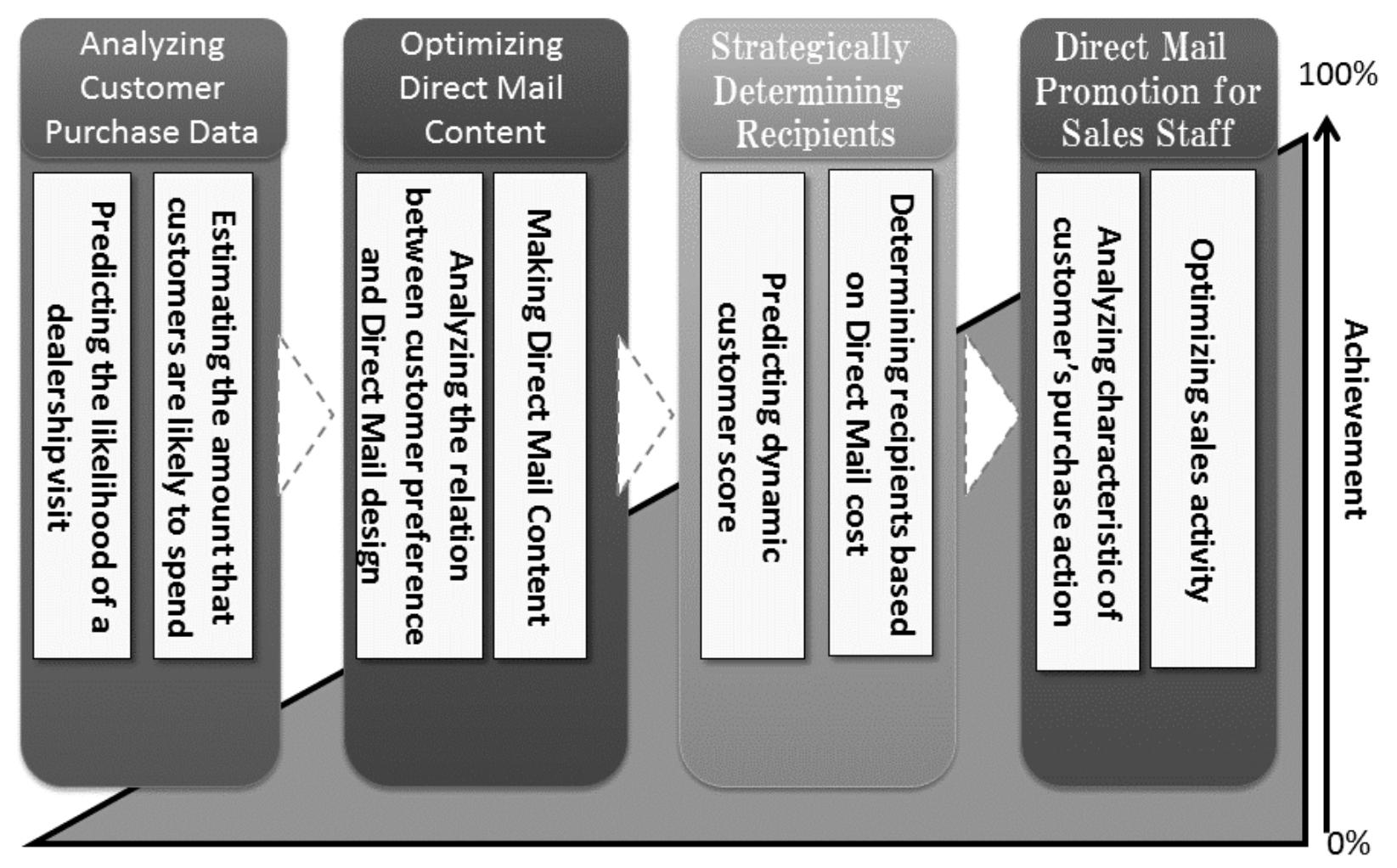

Figure 3: Strategically Applying a Total Direct Mail Model "TDMM": Approach Model 


\subsection{System for Analyzing Customer Purchase Data}

As Table 1 describes, the system for analyzing customer purchase data supports dealers in formulating a direct mail strategy by identifying different premier customer segments.

Table 1: System for Analyzing Customer Purchase Data

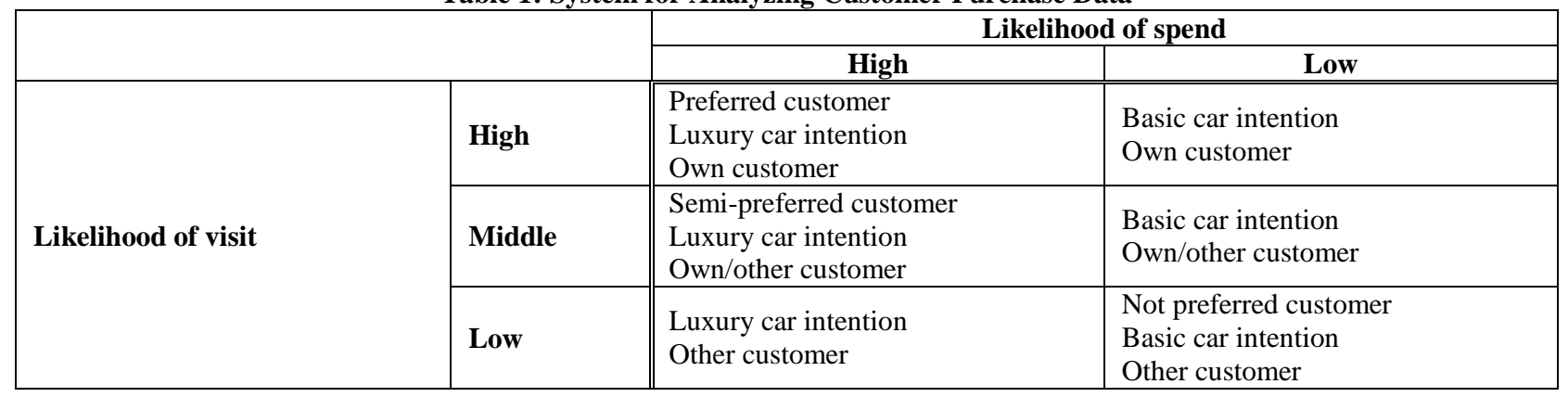

(i) Identifying premier customer segments

Premier customers are first defined according to two different criteria: the likelihood that they will visit the dealership, and the amount of money they can be expected to spend on purchases. This information is based on the purchase process (whether they buy vehicles after coming to the dealer). These two indicators are then combined and used to define the level of the premier customer.

(ii) Predicting the likelihood of a dealership visit

Discriminant analysis is used to score each customer in terms of how likely he or she is to visit the dealership. Past visit data is used to arrive at a discriminant score, using whether the direct mail will lead to a visit as the external criterion and customer attributes as the items. The score is then used to carry out a logistic regression analysis (Tsujitani and Amasaka, 1993) in order to get a regression equation (1) that will calculate the likelihood of a dealership visit.

$P_{i}=\frac{1}{1+\exp \left\{-\left(\alpha_{0}+\sum_{j} \alpha \delta_{i j}\right)\right\}}, \quad i=1,2, \ldots, n$

$i \quad:$ Customer ID number ( $n$ : Number of the customers)

$j \quad$ : Customer attribute ( $J$ : Number of the attributes)

$P_{i} \quad:$ Likelihood that customer $i$ will visit the dealer

$\alpha_{j} \quad$ : Discriminant coefficient

$\delta_{i j} \quad$ : Indicates whether or not customer $i$ has attribute $j$ ( 0 or 1$)$

(iii) Estimating the amount that customers are likely to spend

Regression analysis is used to obtain a regression equation (2) for this calculation, with customer purchase amount as the external criterion and customer attributes as the items. This equation is then used to estimate the amount that customers are likely to spend based on their specific attributes.

$V_{i}=\beta_{0}+\sum_{j} \beta \delta_{i j}, \quad i=1,2, \ldots, n$ 
$V_{i} \quad$ : Amount that customer $i$ is likely to spend

$\beta_{j} \quad$ : Partial regression coefficient

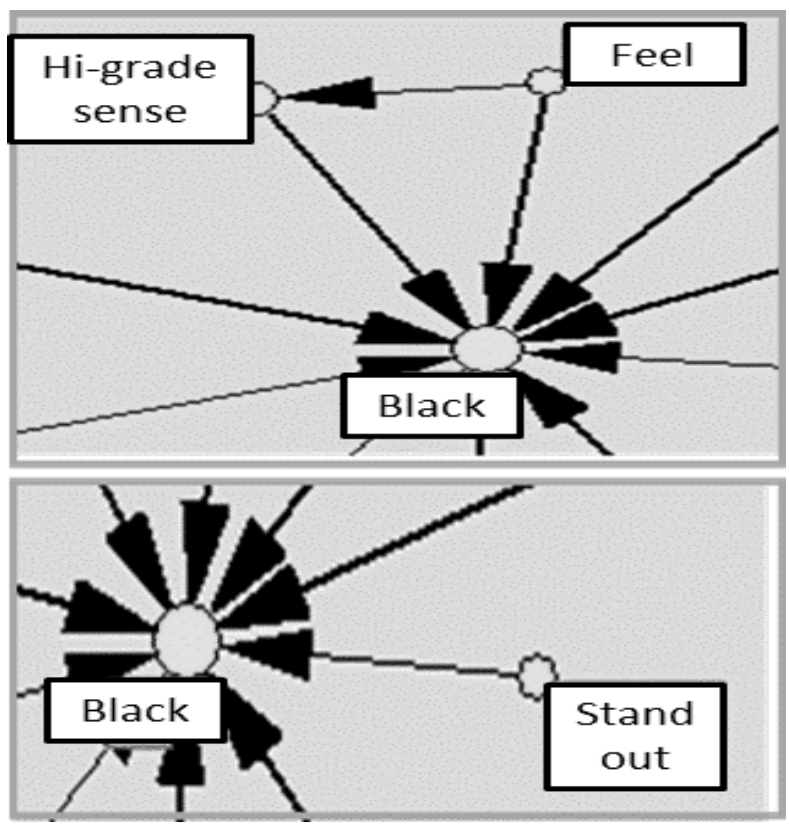

Figure 4: Key Graph

\subsection{System for Optimizing Direct Mail Content}

The system for optimizing direct mail content is used to analyze how customer preferences change in response to changes in direct mail design. To get this information, a Key Graph is used to collect free-response customer feedback on different direct mail designs.

Figure 4 shows an example of a Key Graph. In this example, the authors were able to determine that using a black background gives the design a high-end feel and causes it to stand out. By referring to concepts arrived at using these new insights as well as the system for analyzing customer purchase data, direct mail designers can now create designs that accurately reflect sales strategies and customer preferences.

\subsection{System for Strategically Determining Direct Mail Recipients}

The system for strategically determining direct mail recipients identifies who direct mail should be sent to among the premier customer categories identified using the system for analyzing customer purchase data. Equations (3) to (5) are used to determine the recipients.

$\underset{x_{1}, x_{2}, \ldots, x_{n} \in\{0,1\}}{\operatorname{aximize}} \sum_{i} P_{i} V_{i} x_{i}$

s.t. $\sum_{i} x_{i}=N$ 


$$
L_{j} N \leq \sum_{i} \delta_{i j} x_{i} \leq H_{j} N, \quad j=1,2, \ldots, J
$$

$x_{i} \quad:$ Whether customer $i$ is flagged as a direct mail recipient $(0$ or 1$)$

$N \quad$ : Total number of direct mailings sent

$L_{j} / H_{j} \quad$ : Lower/Upper limit for the percentage of direct mailings sent to customers with attribute $j$

Mathematical programming is used to solve the above equations and determine who should be sent direct mail. The variable $x_{i}$ is the decision variable indicating whether or not a customer $i$ should be targeted as a recipient. The values of the other parameters are determined in advance.

$P_{i}$ (the likelihood of a dealership visit) and $V_{i}$ (amount of money likely to be spent) are determined using the same procedure outlined for the customer purchase data analysis system (section 2.1), once behavioral data (RFM) is added to customer attribute data. Table 2 shows their difference. It is used to determine who should be sent direct mail based on the current level of the premier customer (this takes into consideration different customer behaviors among different premier customer categories).

Table 2: Difference between static customer and dynamic customer

\begin{tabular}{|l|l|l|}
\hline & $\begin{array}{l}\text { Static } \\
\text { (Analyzing Customer Purchase Data) }\end{array}$ & $\begin{array}{l}\text { Dynamic } \\
\text { (Strategically Determining Direct Mail Recipients) }\end{array}$ \\
\hline Definition & $\begin{array}{l}\text { Customer segment who like target car during the } \\
\text { promotion term }\end{array}$ & $\begin{array}{l}\text { Customer segment who like target car most now } \\
\text { Data }\end{array}$ \\
\hline $\begin{array}{l}\text { Life stage } \\
\text { Life style }\end{array}$ & $\begin{array}{l}\text { Life stage } \\
\text { Life style } \\
\text { RFM }\end{array}$ \\
\hline
\end{tabular}

\subsection{Direct Mail Promotion System for Sales Staff}

The direct mail promotion system for sales staff reveals important insights that sales staff can use in order to handle customers when they come to the dealership.

Specifically, the system surveys dealerships to determine what elements are prioritized when someone from the premier customer category purchases a vehicle. As Figure 5 describes, survey data is then subjected to a cluster analysis and principle component analysis to identify characteristics of customer purchase behavior. These results are then communicated to the sales staff.

\section{EFFECTIVENESS OF THE TOTAL DIRECT MAIL MODEL}

As Figure 6 shows, the authors are currently using the TDMM model presented here at Company A in an attempt to increase the percentage of customers that visit the dealer as well as the amount of money they spend when they come in. Specifically, they are using the four systems described above based on Company A's customer information and sales data as well as on customer preferences collected via surveys. 

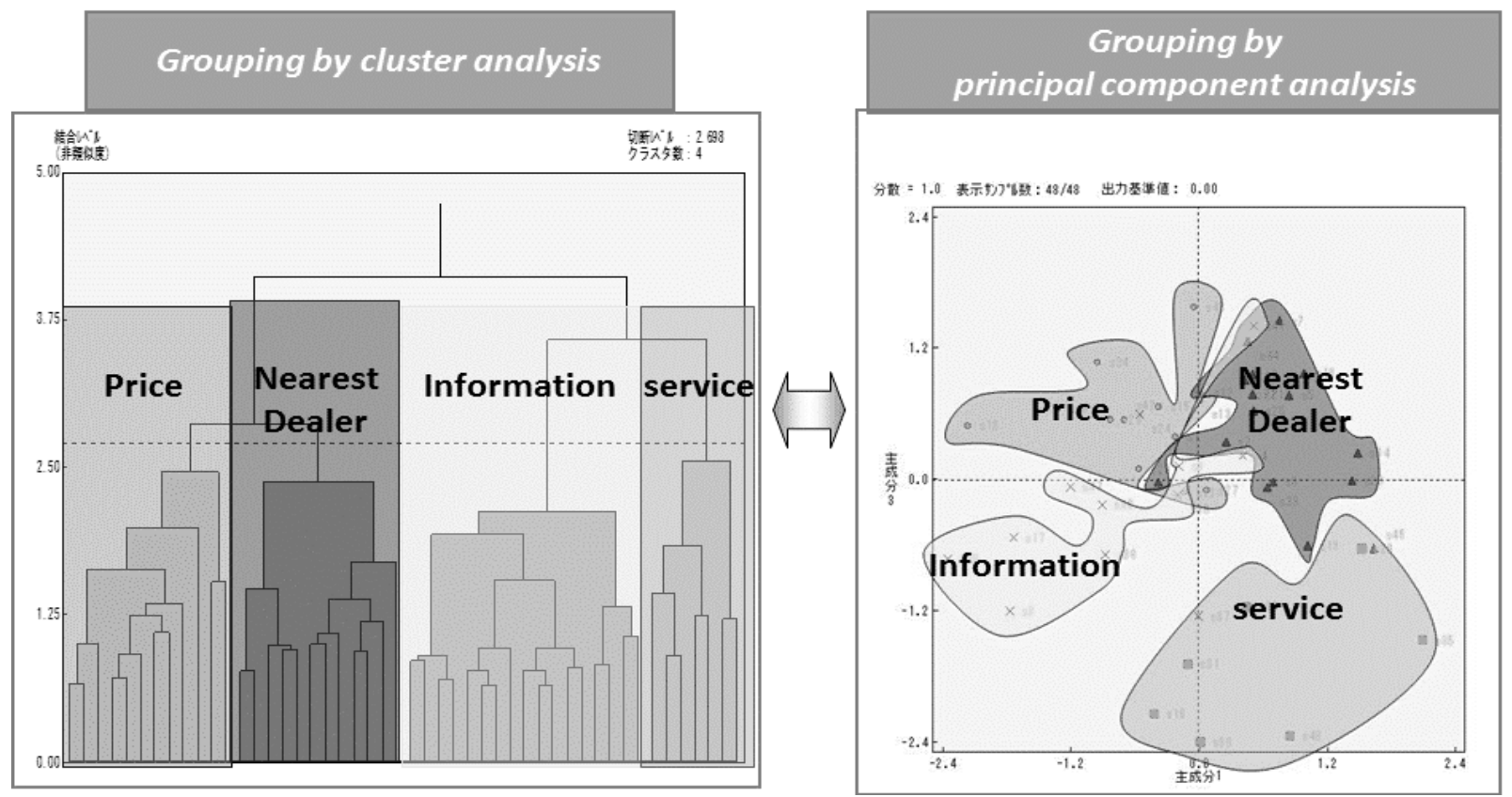

Figure 5: characteristic of customer's purchase action

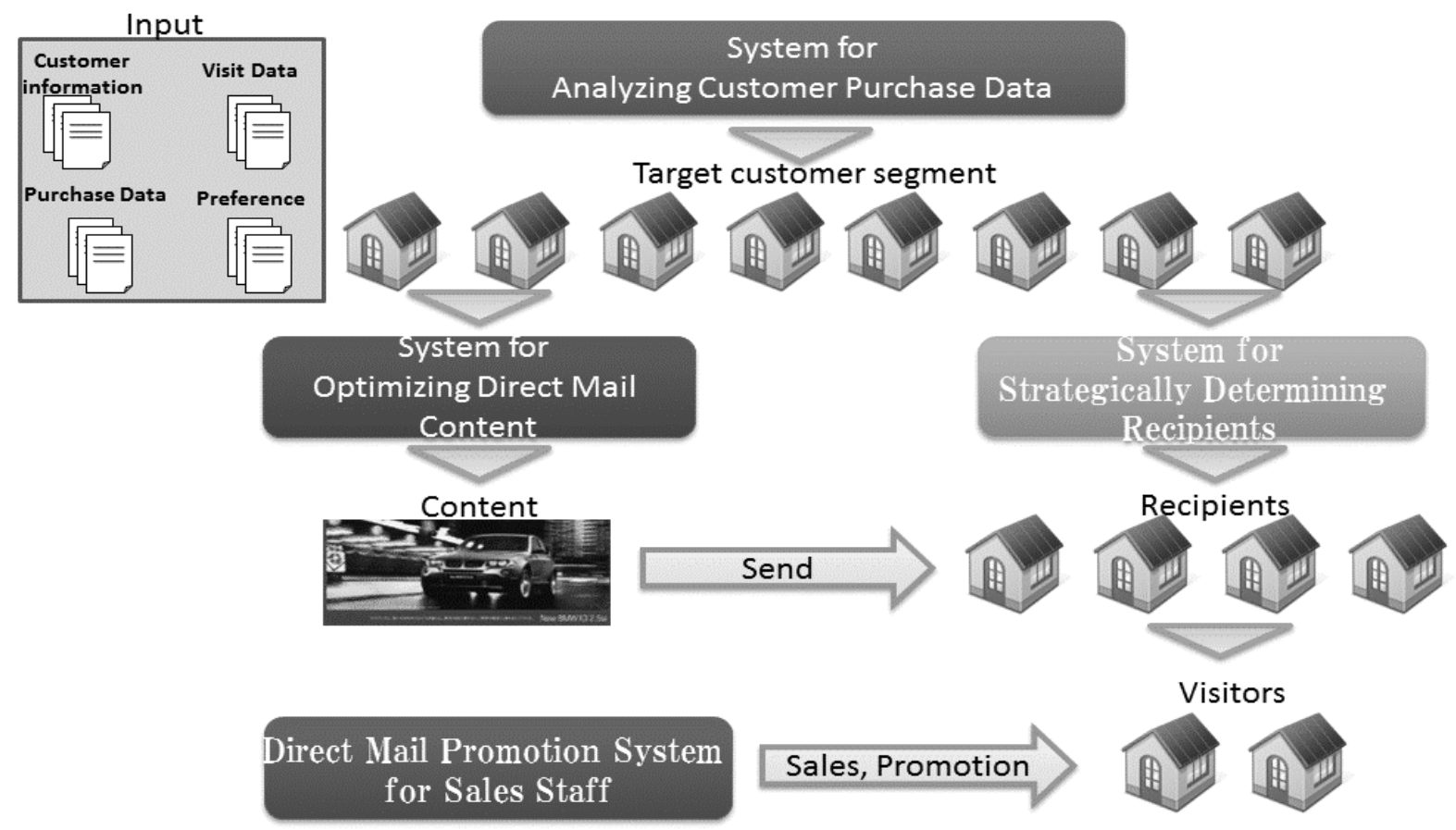

Figure 6: Applying "TDMM"

\section{CONCLUSION}

This paper presents the strategic application of a Total Direct Mail Model "TDMM" for more sophisticated direct mail activities at auto dealerships. The model makes use of customer information and purchase data that dealerships have but are not using effectively. The authors believe that there are still more valuable ways to use the 
data the companies possess, and in the future hope to develop more scientific ways of using it in corporate marketing activities.

\section{AUTHOR INFORMATION}

Hisatoshi Ishiguro is a graduate student of the Graduate School of Science and Engineering at Aoyama Gakuin University, Japan.

Dr. Kakuro Amasaka is a Professor in the College of Science and Engineering at Aoyama Gakuin University, Japan. He received his Ph.D. degree in Precision Mechanical and System Engineering, Statistics and Quality Control at Hiroshima University in 1997. Since joining Toyota Motor Corporation in 1968, He worked as a quality control consultant for many divisions, and the General Manager of the TQM Promotion Division (1998-2000). His specialty is New JIT, Science TQM, Science SQC, Numerical Simulation (CAE) and Customer Science. Now, He has been serving as the vice chairman of JSPM (2003-2007) and JOMSA (2008-2010), the director of JSQC (2001-2003) and the commissioner of the Deming Prize judging committee (2002-present). Now, he is inaugurated as the chairman of JOMSA (2011-present). E-mail: Kakuro_amasaka@ise.aoyama.ac.jp. Corresponding author.

\section{REFERENCES}

1. $\quad$ Amasaka, K. (2004), Science SQC New Quality Control Principle, Springer.

2. Amasaka, K. (2007), "The validity of advanced TMS, a strategic development marketing system -Toyota's scientific customer creative model utilizing New JIT-", International Business and Economics Research Journal, Vol. 6, No. 8, pp. 35-42.

3. Amasaka, K. (2009), "The effectiveness of flyer advertising employing TMS: Key to scientific automobile sales innovation at Toyota", China-USA Business Review, Vol. 8, No. 3, pp. 1-12.

4. Amasaka, K. (2011), "Changes in marketing process management employing TMS: Establishment of Toyota sales marketing system", China-USA Business Review, Vol. 10, No. 6, pp. 539 - 550.

5. Beko, J. and Jagric, T. (2011), "Demand models for direct mail and periodicals delivery services: Results for a transition economy", Applied Economics, Vol. 43, No. 9, pp. 1125-1138.

6. Bell, G. H., Ledolter, J. and Swersey, A. J. (2006), "Experimental design on the front lines of marketing: Testing new ideas to increase direct mail sales", International Journal of Research in Marketing, Vol. 23, No. 3, pp. 309-319.

7. Bult, J. R. and Wansbeek, T. (2005), “Optimal selection for direct mail”, Marketing Science, Vol. 14, No. 4, pp. 378-394.

8. Ferrell, O. C. and Hartline, M. (2005), Marketing Strategy, Thomson South-Western.

9. Ishiguro, H. and Amasaka, K. (2012), "Proposal and effectiveness of a highly compelling direct mail method: Establishment and deployment of PMOS-DM", International Journal of Management and Information Systems, Vol. 16, No. 1, pp.1-10.

10. Ishiguro, H., Kojima, T. and Matsuo, I. (2010), "A highly compelling direct mail method "PMOS-DM": Strategic applying of statistics and mathematical programming", The $4^{\text {th }}$ Spring Meeting of Japan Statistical Society Poster Session, Aoyama Gakuin University. (Student Poster Award)

11. Jonker, J. J., Piersma, N. and Potharst, R. (2006), “A decision support system for direct mailing decision”, Decision Support Systems, Vol. 42, pp. 915-925.

12. Kimura, T., Uesugi, Y., Yamaji, M. and Amasaka, K. (2007), "A study of scientific approach method for direct mail, SAM-DM: Effectiveness of attracting customer utilizing Advanced TMS", Proc. of the $5^{\text {th }}$ Asian Network for Quality Congress, pp. 938-945.

13. Kotler, P. and Keller, K. L. (2006), Marketing Management (12 ${ }^{\text {th }}$ Edition), Prentice Hall.

14. Piersma, N. and Jonker, J. J. (2004), "Determining the optimal direct mailing frequency", European Journal of Operational Research, Vol. 158, No. 1, pp. 173-182.

15. Shimizu, K. (2004), Theory and Strategy of Advertisement, Souse Publishers. (in Japanese)

16. Tsujitani, M. and Amasaka, K. (1993), "Analysis of enumerated data (1): Logit transformation and graph analysis”, Quality Control, Vol. 44, No. 4, pp. 61-66. (in Japanese) 